\title{
Dose-response relation between exposure to two types of hand-arm vibration and sensorineural perception of vibration
}

\author{
Hannu Virokannas
}

\begin{abstract}
Objectives-31 railway workers and 32 lumberjacks were examined to compare the dose-response relation between the exposure to two types of hand-arm vibration and the sensory disturbances in peripheral nerves as evaluated by the vibration perception thresholds (VPTs).

Methods-Clinical examinations were carried out that included measurements of the VPTs, and electroneuromyography (ENMG), and an inquiry to confirm the use of vibrating tools. Diseases of the central nervous system and neuropathies were checked by inquiry and a clinical examination, diabetes was excluded by a blood sample analysis, and the subjects with carpal tunnel syndrome confirmed with ENMG were excluded from the study.
\end{abstract}

Results-Lifetime use of hand held tamping machines (railway workers) and chain saws (lumberjacks) had a significant correlation with the VPTs at frequencies from 32 to $500 \mathrm{~Hz}$. The increase of the VPTs $(250 \mathrm{~Hz})$ in relation to use of vibrating tools was 1.8 -fold higher on average in the whole group and $2 \cdot 3$-fold higher in the young $(<45)$ railway workers who had used hand held tamping machines, than in the corresponding groups of lumberjacks, who had used chain saws, whereas the frequency weighted acceleration of vibration in tamping machines was fourfold.

Conclusion-There was a significant dose-response relation between the exposure to hand-arm vibration and the VPTs. The VPTs as a function of the frequency weighted acceleration of vibration and the exposure to vibration gave promising results for assessment of the risk of damage to sensory nerves induced by vibration.

(Occup Environ Med 1995;52:332-336)

Department of Public Health Science and General Practice, University of Oulu, Aapistie 1, FIN-90220 Oulu, Finland

$\mathrm{H}$ Virokannas

Correspondence to: Dr Hannu Virokannas, Department of Public

Health Science and General

Practice, University of Oulu,

Aapistie 1, FIN-90220

Oulu, Finland.

Accepted 19 January 1995 vibration in workers exposed to hand-arm vibration..$^{1-4}$ An impairment in perception of vibration seems to be an early sign of nerve
Keywords: dose-response; hand-arm vibration

Several papers published over the past few years have indicated that the vibration perception threshold (VPT) is a useful measure to examine sensory nerve damage induced by injury. ${ }^{5}$ According to the previous studies, hand-arm vibration first disturbs the high frequencies of the VPTs. ${ }^{127}$ This indicates disturbances in the fast adapting II fibres and Pacinian corpuscles, ${ }^{8}$ although damage later seems also to spread to the low-frequency area, which indicates further disturbances in the slow adapting I and fast adapting I fibres and in Meisner's corpuscles. ${ }^{9}$ Impairment of the sense of vibration has also been long used in clinical neurology as an indicator of peripheral neuropathy, ${ }^{10-12}$ and it has even been recommended for use in screening. ${ }^{13}$

Apart from exposure to vibration, other factors also influence the VPT. For example, the VPTs are age dependent, ${ }^{14}$ the height of the subjects should be taken into account, because taller subjects have higher VPTs than shorter ones, ${ }^{12}{ }^{15}$ and the VPTs have been reported to be slightly higher in physical than in mental work. ${ }^{13}$ Also, diseases affecting the central nervous system ${ }^{16}$ and neuropathies ${ }^{17}$ such as diabetes ${ }^{12}$ and the carpal tunnel syndrome ${ }^{18}$ disturb sensory nerve function, and the temperature of the skin has an effect on the VPTs. ${ }^{19}$

Until now there is only scant knowledge available on the dose-response relation between the exposure to various vibrating tools and sensory nerve damage. ${ }^{7}$ The aim of this study was, firstly, to compare the disturbances in the peripheral sensory nerves caused by two types of vibration with the VPTs as an indicator and, secondly, to examine the relation between the exposure to vibration expressed as a frequency weighted acceleration of vibration ${ }^{20}$ and the VPTs.

\section{Material and methods}

SUBJECTS

The study population consisted of 70 workers exposed to hand-arm vibrations-37 railway workers and 33 lumberjacks. Clinical examinations including measurements of the VPTs, electroneuromyography (ENMG), and an inquiry to confirm the use of vibrating tools were carried out. On the bases of the clinical findings, seven subjects were excluded: two railway workers had signs of polyneuropathy in the ENMG measurements and four railway workers and one lumberjack had findings indicative of carpal tunnel syndromeTinell's test and Phalen's test were positive and the ENMG measurements of the median nerve were considered indicative of CTS.

In the final study group, the railway workers $(\mathrm{n}=31)$ were two years older, $2 \mathrm{~cm}$ taller, 
Table 1 Characteristics of the study groups (mean (SD))

\begin{tabular}{|c|c|c|c|c|}
\hline Occupation & $n$ & $\begin{array}{l}\text { Age } \\
(y)\end{array}$ & $\begin{array}{l}\text { Height } \\
(\mathrm{cm})\end{array}$ & $\begin{array}{l}\text { Weight } \\
(\mathrm{kg})\end{array}$ \\
\hline $\begin{array}{l}\text { Railway workers } \\
\text { Lumberjacks }\end{array}$ & $\begin{array}{l}31 \\
32\end{array}$ & $\begin{array}{l}44 \cdot 4(9 \cdot 4) \\
42 \cdot 4(10 \cdot 4)\end{array}$ & $\begin{array}{l}174 \cdot 1(5 \cdot 9) \\
172 \cdot 1(5 \cdot 5)\end{array}$ & $\begin{array}{l}80 \cdot 8(15 \cdot 8) \\
71 \cdot 4(9 \cdot 2)\end{array}$ \\
\hline
\end{tabular}

and slightly heavier than the lumberjacks $(\mathrm{n}=32$, table 1$)$. A history of an attack of white finger was reported by $45 \%$ of the railway workers and $38 \%$ of the lumberjacks. According to the inquiry and the clinical assessment, the subjects did not have any diseases of the central nervous system or other neurological diseases, and none had diabetes confirmed by an analysis of blood samples. The subjects had not been exposed to industrial neurotoxic agents.

The exposure to hand-arm vibration was caused by hand held tamping machines in the railway workers and by chain saws in the lumberjacks. The frequency weighted acceleration of hand-arm vibration according to the international standard ISO $5349^{20}$ has been found to be $2-4 \mathrm{~m} / \mathrm{s}^{2}$ in chain saws ${ }^{21}$ and $10-14 \mathrm{~m} / \mathrm{s}^{2}$ on the handlebars of hand held tamping machines. ${ }^{2223}$ The railway workers ( $\mathrm{n}$ $=31$ ) had worked for an average of 16 years and the lumberjacks $(n=32)$ for 20 years.

Both occupational groups were asked in an inquiry about their exposure time by the same methods. "What kind of vibrating tools have you used? How many years have you used them? How many hours have you used them per year?" The exposure time was calculated with self estimated annual use of vibrating tools and vehicles (hours) and number of years of exposure to vibration. The mean (SD) total duration of exposure to vibration was 8050 (3500) hours among the railway workers and 21250 (10 950) hours among the lumberjacks. In the group of railway workers $95 \%$ of the exposure was caused by tamping machines and in the group of lumberjacks $98 \%$ of the exposure was caused by chain saws.

\section{METHODS}

The VPTs were measured with the modified Bruel and Kjaer's equipment described in previous studies, ${ }^{724}$ with the limits technique method. The vibration exciter was regulated by a sine generator and the vibration was measured by an accelerometer inserted

Table 2 Relation between estimates of the effects of total duration of exposure to vibration of hand held tamping machines ( $B_{R}$, railway workers) and chain saws ( $B_{L}$ lumberjacks) on the vibration perception thresholds (VPT) and corresponding $P$ values from linear regression analysis

\begin{tabular}{lllllll}
\hline \multirow{2}{*}{$\begin{array}{l}\text { VPT frequency } \\
(H z)\end{array}$} & \multicolumn{2}{l}{ Railway workers $(n=31)$} & & \multicolumn{2}{l}{ Lumberjacks $(n=32)$} & \\
\cline { 2 - 3 } & Coefficient $B_{R}$ & $P$ value $\left(B_{R}\right)$ & & Coefficient $B_{L}$ & Pvalue $\left(B_{L}\right)$ & $\left.B_{R} / B_{L}\right)$ \\
\hline 500 & 0.001059 & 0.0034 & 0.000566 & 0.0010 & 1.9 \\
250 & 0.001596 & 0.0015 & 0.000909 & 0.0001 & 1.8 \\
125 & 0.001092 & 0.0171 & 0.000688 & 0.0001 & 1.6 \\
63 & 0.001042 & 0.0038 & 0.000500 & 0.0003 & 2.1 \\
32 & 0.000731 & 0.0079 & 0.000366 & 0.0004 & 2.0 \\
16 & 0.000551 & 0.0651 & 0.000292 & 0.0030 & 1.9 \\
\hline
\end{tabular}

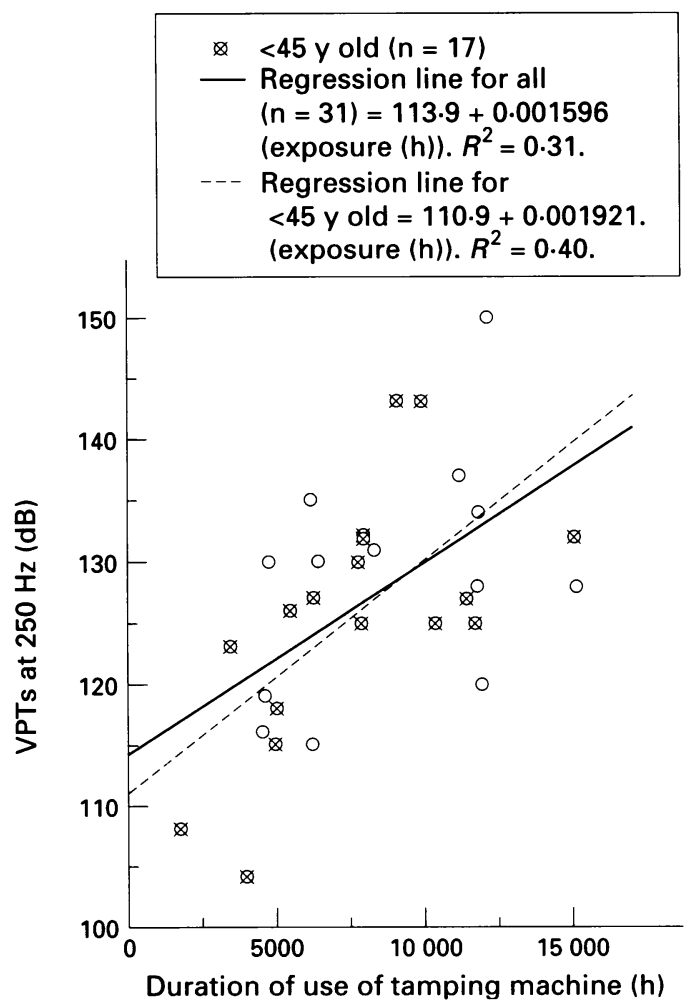

Figure 1 Vibration perception thresholds (VPTs) at the frequency of $250 \mathrm{~Hz}$ as a function of the duration of use of hand held tamping machines in the railway workers.

between the exciter and the vibrating head (diameter $2.6 \mathrm{~mm}$ ). A beam balance controlled the force $(0.20 \mathrm{~N})$, which was used to stabilise the contact force of the vibrating head on the skin of a finger. The level of acceleration of vibration was measured with a charge amplifier and recorded on paper with a level recorder. The acceleration was increased by $3 \mathrm{~dB} / \mathrm{s}$. The subject was asked to press the button immediately he felt vibration on his finger tip. The VPTs were measured at six frequencies from 16 to $500 \mathrm{~Hz}$ from the distal phalanx of the middle finger on the palmar side of the right hand. The result was the mean of three successive values recorded in $\mathrm{dB}$ acceleration, with a reference acceleration of $10^{-6} \mathrm{~m} / \mathrm{s}^{2}$.

The temperature of the skin of the finger was measured with a YSI 400-series probe (Yellow Springs Instrument, USA). The hand was warmed in a water bath before the test to above $28^{\circ} \mathrm{C}$ to avoid changes in the VPTs induced by temperature. ${ }^{19}$

The ENMG measurements were carried out with a commercial ENMG measuring system (Medelec 91a) with conventional techniques of measurements of nerve conduction, and the values were corrected for the skin temperature whenever necessary. In the median nerve, both a distal sensory conduction velocity of less than $42 \mathrm{~m} / \mathrm{s}$ and a motor distal latency of less than $4.4 \mathrm{~ms}$ were considered indicative of carpal tunnel syndrome.

Statistical analyses were performed by linear correlation, and a linear regression model was calculated for both the occupational groups between the VPTs and the total duration of exposure to hand-arm vibration. The effects of vibration were calculated in the 
Figure 2 Vibration perception thresholds (VPTS) at the frequency of $250 \mathrm{~Hz}$ as a function of the duration of use of chain saws in the lumberjacks.
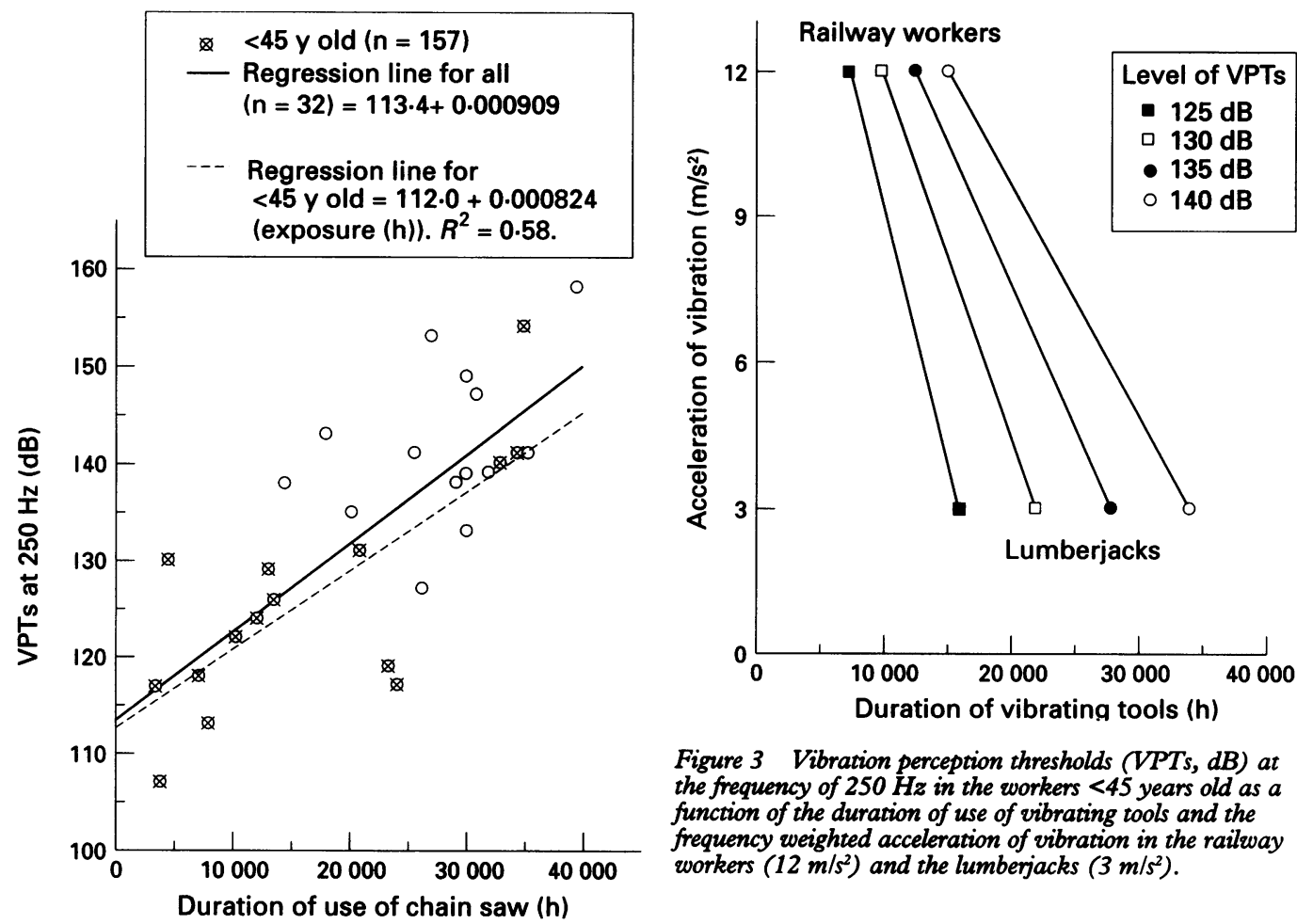

Figure 3 Vibration perception thresholds (VPTs, dB) at the frequency of $250 \mathrm{~Hz}$ in the workers $<45$ years old as a function of the duration of use of vibrating tools and the frequency weighted acceleration of vibration in the railway workers $\left(12 \mathrm{~m} / \mathrm{s}^{2}\right)$ and the lumberjacks $\left(3 \mathrm{~m} / \mathrm{s}^{2}\right)$. whole study group and in the two age groups for both the occupations. The subjects older than the median of age (45) were included in one age group and the younger ones in the other.

\section{Results}

The total duration of exposure to hand-arm vibration had a significant linear correlation with the VPTs on a logarithmic (dB) scale in all the railway workers $(r=0.55-0.47$, $P=0.017-0.001)$ and all the lumberjacks $(r=0.77-0.59, \mathrm{P}=0.003-0.0001)$ at all frequencies, expect at $16 \mathrm{~Hz}$ in the railway workers. According to the regression equations between the VPTs and the duration of use of vibrating tools, the increase of the VPTs in relation to the use of vibrating tools was $1 \cdot 6-2 \cdot 1$ times stronger for hand held tamping machines than chain saws (table 2, figs 1 and 2).

The results were also analysed in the two age groups. In the group of workers $<45$ years old (17 railway workers and 15 lumberjacks) a connection between the VPT and the total exposure time to vibration was significant at the frequencies of $32-500 \mathrm{~Hz}$, and relations between the effects of hand held tamping machines and chain saws on the VPTs varied from $2 \cdot 2$ to 2.9 (table 3 ). The effect of tamping machines on the VPTs was slightly stronger and that of chain saws slightly weaker in the young age group than in all the subjects (figs 1 and 2). In the group of workers $>45$ years old (17 railway workers and 15 lumberjacks) the corresponding connection was not significant in the regression model, except at $250 \mathrm{~Hz}$ in the lumberjacks $(P=0.0474)$.

In fig 3, the VPTs at $250 \mathrm{~Hz}$ in the railway workers and the lumberjacks are presented as a function of the exposure to vibration and the frequency weighted acceleration of vibration in the workers $<45$ years old (17 railway workers and 15 lumberjacks). According to these results, a VPT of $130 \mathrm{~dB}$ was expected after use of a tamping machine for 9900 hours and a chain saw for 21800 hours. Correspondingly, a VPT of $140 \mathrm{~dB}$ was expected after use of a tamping machine for 15100 hours and a chain saw for 34000 hours.

\section{Discussion}

Because hand-arm vibration may cause peripheral neurological disorders independently of vascular disturbance, ${ }^{525}$ a method for early detection of neuropathy induced by vibration is also needed. We used the VPTs to examine damage to sensory nerves induced by vibration in workers exposed to two types of hand-arm vibration. There is not much information available on the effects of the different vibrating tools on nerves ${ }^{1-3}$ and the doseresponse relation between the exposure to 
vibration and the VPTs. ${ }^{7}$ In our study, 31 railway workers and 32 lumberjacks were examined to compare sensory disturbances in the peripheral nerves (as evaluated by the VPTs) caused by the use of hand held tamping machines and chain saws. Even the VPTs are not specific to neural disorders induced by vibration. The VPTs increased significantly in relation to the total duration of exposure to hand-arm vibration in both occupations, and the use of hand held tamping machines affected the VPTs more strongly than did the use of chain saws.

The frequency weighted acceleration of vibration ${ }^{20}$ in the hand held tamping machines was fourfold that in the chain saws, and the increase of the VPTs in relation to use of vibrating tools was 1.8 -fold in the whole group of railway workers and $2 \cdot 3$-fold in those $<45$ years old compared with the lumberjacks at $250 \mathrm{~Hz}$, at which frequency the effect of vibration on the VPTs was maximal. It is not known whether the frequency weighted acceleration of vibration adequately indicates a disturbance in peripheral nerves. For instance, this weighting system may underestimate the risk of white finger caused by high frequency vibration. ${ }^{26}$ Here, the effect of frequency weighted acceleration of vibration seems to behave logically, but as there were only two types of vibration included in the comparison, more evidence is needed to confirm this finding.

The distributions of age were similar in the two occupational groups, and the mean ages differed only by two years. Unfortunately, a correlation between age and exposure to vibration was different in the railway workers and lumberjacks and that made it difficult to interpret the results of multiple regression analysis (exposure and age). Therefore, the results were also calculated in the two age groups. In the whole group and in the group of young workers there was a significant connection between the exposure to vibration and the VPTs in both occupations. The relation between the exposure to vibration and the VPTs differed only slightly in these groups. Although the number of subjects was small in the younger age group, their result implied that age of the subjects did not seriously interfere with the findings in the whole group. In the group of older workers a deviation of the VPT values was greater, probably for other reasons, and in this small group a connection was not significant, except at $250 \mathrm{~Hz}$.

Until now, there have not been enough data published to assess the risk of neural damage caused by hand-arm vibration. ${ }^{6}{ }^{25}$ Here, the VPTs in the younger age group expressed as a function of the frequency weighted acceleration of vibration and the exposure to vibration (fig 3) gave promising results for the assessment of risk.

In a retrospective inquiry the annual use of vibrating tools was not easy to remember exactly, and this caused inaccuracy in the results. There was, however, no reason why the results reported did not reflect the true exposure in the same way in the two groups.
The question on duration of exposure was asked in the same way for both the occupational groups.

Both of the occupations examined involved heavy manual work, but there was a difference in the periods of exposure to vibration. The lumberjacks had used chain saws almost every working day for more than 1000 hours a year. Correspondingly, the railway workers had used hand held tamping machines for about 500 hours a year in shorter periods. It is believed that long continuous exposure may be more harmful, at least as far as vibration white finger is concerned. ${ }^{27}$ Not very much is known about the influence of intermittent exposure to vibration on damage to nerves. There are also differences in the vibration spectra: the peak values for hand held tamping machines range within $40-60 \mathrm{~Hz}^{23}$ and those for chain saws within $120-150 \mathrm{~Hz}^{21}$ It is suggested that the frequencies of $250-350 \mathrm{~Hz}$ and possibly higher may be the most harmful to nerves. ${ }^{128}$ Both differences in the annual duration of exposure and the spectrum of vibration may influence the results and probably increase the effect of the use of chain saws on the VPTs.

The distribution of height of the workers was similar in the two occupations and it was not likely that the effect of height ${ }^{12}$ could have significantly biased the results on the VPTs. Other important factors that affected the VPTs were examined in the clinical study. Diseases of the central nervous system and neuropathies were checked with an inquiry and a clinical examination, diabetes was excluded by a blood sample analysis, and the subjects with carpal tunnel syndrome, confirmed with ENMG, were excluded from the study. This measuring system with the modified Bruel and Kjaer's equipment has been used in many Finnish vibration studies. ${ }^{724} 25$ The principle of our measuring method is the same as in the commercial Bruel and Kjaer's equipment (Vibrometry System type 9627) and it is not likely that the finding (relation between the exposure to vibration and VPTs) should be perceived only by our method. The VPT values are not directly comparable, because in our study the thresholds were measured only when the acceleration of vibration was increased (upper threshold), whereas in the system of Bruel and Kjaer the area of vibration perception (upper and lower threshold) is measured and the mean value of the VPT is used. The method of measuring VPT is non-invasive and easy to carry out, but good cooperation with the subjects and a training period before measurement is necessary. ${ }^{29}$ The VPTs are also dependent upon temperature. ${ }^{19}$ The skin temperature of the finger was therefore controlled, and the hands were warmed up whenever necessary.

\section{Conclusion}

The results showed a dose-response relation between the exposure to hand-arm vibration and the VPTs. Neural disturbances measured with VPT may be related to the acceleration 
of vibration. In our study the frequency weighted acceleration of vibration in the hand held tamping machines was fourfold that in the chain saws, and the increase of the VPTs in relation to the use of vibrating tools in the group of railway workers was about twofold that in the lumberjacks. The VPTs as a function of the frequency weighted acceleration of vibration and the exposure to vibration gave promising results for assessment of the risk of damage to sensory nerves induced by vibration.

1 Lundborg G, Sollerman C, Strömberg T, Pyykkö I, Rosen B. A new principle for assessing vibrotactile sense in vibration-induced neuropathy. Scand $\mathcal{f}$ Work Environ vibration-induced neu

2 Brammer AJ, Piercy J, Nohara S, Nakamura H, Auger PL, Haines AT, et al. Vibrotactile thresholds in operators of vibrating hand held power tools. In: Okada A, Taylor W, Dupuis $\mathrm{H}$, eds. Hand-arm vibration. Kanazawa: Kyoei Press, 1990:221-3.

3 Lundström R, Strömberg T, Lundborg G. Vibrotactile perception threshold measurements for diagnosis of sensory neuropathy. Int Arch Occup Environ Health 1992; 64:201-7.

4 Ess G, Dupuis $H$. Intraindividual variability of vibration sensitivity at the finger tips. In: Dupuis $\mathrm{H}$, Christ $\mathrm{E}$, Sandover J, Taylor W, Okada A, eds. Proceedings of the 6 th International Conference on Hand-Arm Vibration, Bonn, Germany. 19-22 May 1992. Essen: Druckzentrum Sunn, Germany. 19-22 May 1992. Essen:

5 Brammer AJ, Taylor W, Piercy J. Assessing the severity of the neurological component of the hand-arm vibration the neurological component of the hand-arm vibration syndrome.

6 Brammer A, Pyykkö I. Vibration-induced neuropathy: detection by nerve conduction measurements. Scand $\mathcal{F}$ Work Environ Health 1987;13:279-83.

7 Virokannas H. Vibration perception thresholds in workers exposed to vibration. Int Arch Occup Environ Health 1992;64:377-82.

8 Johansson RS, Landström U, Lundström R. Sensitivitiy to edges of mechanoreceptive afferent units innervating the glabrous skin of the human hand. Brain Res 1982; 244:27-32.

9 Johansson RS, Landström U, Lundström R. Responses of mechanoreceptive afferent units in the glabrous skin of the human hand to sinusoidal skin displacements. Brain Res 1982;244:17-25.

10 Gregersen G. Vibratory perception threshold and motor conduction velocities in diabetics and non-diabetics. Acta Med Scand 1968;183:61-5.
11 Bergström J, Lindblom U, Noree L-O. Preservation of peripheral nerve function in severe uremia during treat-
ment with low protein high calorie diet and surplus of ment with low protein high calorie diet and surplus of
essential amino acids. Acta Neurol Scand 1975;51: essential

12 Wiles PG, Pearce SM, Rice PJ, Mitchell JM. Vibration perception threshold: influence of age, height, sex, and smoking, and calculation of accurate centile values. Diabet Med 1991;8:157-61

13 Halonen P. Quantitative vibration perception thresholds in healthy subjects of working age. Eur f Appl Physiol 1986; 54:647-55.

14 Verrillo RT. Change in vibrotactile thresholds as a function of age. Sensory Processes 1979;3:49-59.

15 Era P, Jokela J, Suominen H, Heikkinen E. Correlates of vibrotactile thresholds in men of different ages. Acta Neurol Scand 1986;74:210-7.
Nibrotactile thresholds in ment

16 Roland PE, Nielsen VK. Vibratory threshold in the hands. Comparison of patients with suprathalamic lesions with normal subjects. Arch Neurol 1980;37:775-9.

17 Juntunen J, Haltia M. Polyneuropathies in occupational neurology: pathogenetic and clinical aspects. Acta Neurol Scand 1982;66 (suppl):59-73

18 Jetzer T. Use of vibration testing in the early evaluation of workers with carpal tunnel syndrome. $f$ Occup $\mathrm{Med}$ 1990;33:117-20.

19 Koradecka D. Changes in the threshold of vibration sensibility depending on skin temperature. Acta Physiologica Poland 1974;25:207-14.

20 International Organisation for Standardization. Mechanical vibration-Guidelines for the measurement and the assessment of human exposure to hand transmitted vibration. Geneva: ISO, 1986. (International Standard ISO 5349.)

21 Starck J. Characteristics of vibration, hand grip force, and hearing loss in vibration syndrome. Kuopio, Finland: hearing loss in vibration syndrome. Kuopio, Finland:
University of Kuopio 1984. (Original reports 4/1984, natural sciences.)

22 Niskanen J, Anttonen H, Pekkarinen A, Raunu P. Hand held tamping machines as a health risk to track maintenance workers. In: Proceedings of the 39th Nordic Work Environment Congress. 12-14 September, Aulanko, Finland. Helsinki: Institute of Occupational Health, 1990:242-3.

23 Virokannas $\mathrm{H}$, Anttonen $\mathrm{H}$, Niskanen J. Health risk assessment of noise, hand-arm vibration, and cold in railway track maintenance. International fournal of Industrial Ergonomics 1994;13:247-52.

24 Aatola S, Färkkilä M, Pyykkö I, Korhonen O, Starck J. Measuring method for vibration perception threshold of fingers and its application to vibration exposed workers. fingers and its application to vibration exposed

25 Färkkilä M, Aatola S, Stack J, Pyykkö I, Korhonen O. Vibration-induced neuropathy among forestry workers. Acta Neurol Scand 1985;71:221-5.

26 Griffin MJ. Handbook of human vibration. London: Academic Press, 1990

27 International Organisation for Standardization. Principles for the measurement and the evaluation of human exposure to vibration transmitted to the hand Geneva: ISO 1977. (Draft International Standard ISO/DIS 5349.)

28 Pelmear PL, Leong D, Taylor W, Nagalingam M, Fung D. Hand-arm vibration syndrome health effects and safety standards. In: Okada A, Taylor W, Dupuis H,
eds. Hand-arm vibration. Kanazawa: Kyoei Press, 1990:63-6.

29 Grunert BK, Wertsch JJ, Matloub HS, McCallum-Burke $\mathrm{S}$. Reliability of sensory threshold measurement using a digital vibrogram. F Occup Med 1990:32:100-102. 